\title{
Looking beyond legality: understanding the context of female sex workers in greater Cairo, Egypt
}

\author{
I.A. Kabbash, I. Abdul-Rahman ${ }^{2}$ and Y.A. Shehata ${ }^{3}$
}

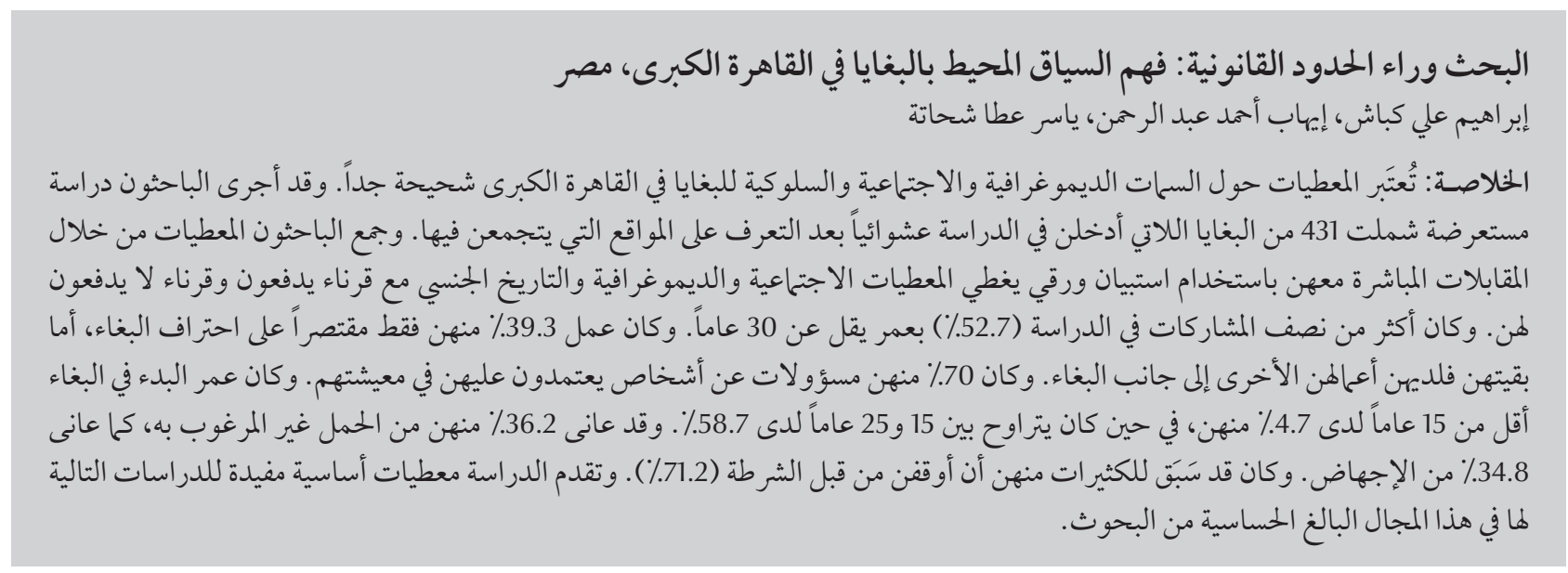

ABSTRACT Data on demographic, social and behavioural characteristics of female sex workers in greater Cairo are very scarce. A cross-sectional study was conducted with 431 randomly selected sex workers after mapping of sites where they gather. Data collection was performed by direct interviewing using a questionnaire sheet covering sociodemographic data and sexual history with paying and non-paying partners. More than one half of participants $(52.7 \%)$ were aged $<30$ years. Only $39.3 \%$ were exclusively working as sex workers while the rest had other jobs beside sex work. Almost 70\% were responsible for dependants. The age of first selling sex was $<$ 15 years for $4.7 \%$ of the women and $15-25$ years for $58.7 \%$. Unwanted pregnancies were experienced by $36.2 \%$ and $34.8 \%$ had had an abortion. Many participants had ever been arrested by the police (71.2\%). The study has provided some useful background data for further studies in this very sensitive area of research.

Par delà la légalité : comprendre le contexte des professionnelles du sexe dans le Grand Caire (Égypte)

RÉSUMÉ Les données sur les caractéristiques démographiques, sociales et comportementales des professionnelles du sexe dans le Grand Caire sont très rares. Une étude transversale a été menée auprès de 431 professionnelles du sexe sélectionnées aléatoirement après avoir cartographié leurs lieux de rassemblement. Le recueil des données a été réalisé par entretien direct à l'aide d'un questionnaire couvrant les données sociodémographiques et les antécédents sexuels avec des partenaires payants ou non. Plus de la moitié des participantes (52,7\%) avait moins de 30 ans. Seules 39,3\% exerçaient exclusivement cette activité professionnelle alors que les autres avaient un autre emploi en plus de leur activité de professionnelle du sexe. Près de $70 \%$ avaient des personnes à charge. L'âge de la première vente de services sexuelles était inférieur à 15 ans pour 4,7\% des femmes et se situait entre 15 à 25 ans pour 58,7\%. Au total, 36,2 \% avaient eu une grossesse non désirée et 34,8 \% avaient subi un avortement. Les participantes étaient nombreuses à avoir été arrêtées par la police (71,2\%). L'étude a fourni des données contextuelles utiles pour la réalisation d'autres études approfondies dans ce domaine de recherche très sensible. 


\section{Introduction}

Female sex workers (FSW) represent an important public health issue [1-5]. They have long been considered as reservoirs for sexually transmitted infections (STIs) [2] and it has been documented that higher rates of HIV and other STIs exist among those involved with sex work than in most other populations [5]. Commercial sex is also associated with complex socioeconomic problems such as social and moral deprivation, poverty, violence and drug misuse [6].

Although greater Cairo is home to nearly 20\% of the Egyptian population [1], there are little data available on the demographic, social and behavioural characteristics of FSW. Studies carried outside Egypt have indicated that the rates of HIV infection are highest among at-risk populations such as FSW, because of their high-risk behaviours (having multiple partners with little or no protective measures) [7-10]. There are no reliable estimates of the number of sex workers in Egypt nor is there information on the types of sex work that women are mostly involved in. This study aimed to describe the characteristics of FSW in greater Cairo, Egypt, to provide important baseline information needed for programmes addressing harm reduction for HIV infection among this most at-risk population.

\section{Methods}

\section{Study setting}

This cross-sectional study was conducted in greater Cairo which includes 3 governorates (Cairo, Giza and Qualyobia) and accommodates a population of nearly 14 million [1]. The target population was FSW. Different categories of FSW were identified by 3 focus group discussions which were conducted before starting fieldwork. Each focus group included
6-8 FSW recruited by the Al-Shehab project. Al-Shehab is a nongovernmental organization (NGO) which had a long experience working with sex workers on different issues related to prevention of HIV infection and providing social and legal support in different regions of greater Cairo. From the focus groups and from the experience of fieldwork done by AlShehab we identified 6 categories of FSW and the main sites where they gather: street FSW; FSW in bars and nightclubs; dancers; FSW in brothels; FSW in coffeehouses; and FSW in hotels.

\section{Sample size and technique}

Based on a prevalence of HIV among sex workers of $0.3 \%$ and an expected error margin of $3 \%$, the total sample size was estimated as less than 400 . So we aimed to recruit between 400-500 women to ensure a high level of validity of the results.

For each category of FSW a category of site was selected so as to locate FSW for interview (street, nightclub/ bar, hairdressing shop where dancers gather to prepare themselves before working, brothel and coffee shop). Sex workers at hotels were difficult to access as the researcher did not obtain approval from hotel management to conduct fieldwork there, so they were not included in the study. Data collectors were directed to randomly selected sites to collect data from all FSW available at the interview time. The process was repeated and another group of sites were randomly chosen and visited until the desired sample size was obtained. For each category a suitable time for visiting the site was identified to ensure cooperation of the study subjects and avoid interfering with their work needs. A suitable place which offered comfortable conditions and confidentiality was chosen by data collectors to conduct the interviews. A total of 431 women were interviewed. The rate of refusal to participate was $3 \%$.

\section{Data collection methods and tools}

The study was conducted during the period from August 2009 to April 2010. Data collection was performed through interviews with study subjects by trained interviewers who were 6 ex-FSW who used to participate in Al-Shehab's outreach programme for harm reduction for HIV infection among sex workers.

A questionnaire sheet was used to collect data on the behaviours of FSW. This was adapted from a behavioural surveillance survey questionnaire published by Family Health International [11]. Modifications were made to adjust for the situation of sex work in Egypt, based on the experience of the research team and consultation with experts from AlShehab who had worked previously with this group. The questionnaire included questions covering the following: background characteristics; marriage, family and work; sexual history (age of first time selling sex, duration of sex work and information about paid/unpaid sexual partners). A pilot study was conducted in order to test the questionnaire to ensure its suitability for data collection.

Data collection was anonymous. Confidentiality was ensured during the whole study period where no data were linked to names or specific persons. No pressure of any kind was used for recruitment of the study subjects. Witnessed verbal consent was taken before the interview. The study objectives and content of the questionnaire were explained to the women recruited before starting data collection. The collected data were only used for research purposes according to the study objectives and for the benefit of the study subjects. Financial incentives were given to the recruited FSW for participating in the study to compensate for the time lost during the interview. This incentive helped to minimize the refusal rate. 


\section{Statistical analysis}

The collected data were organized, tabulated and statistically analysed using SPSS, version 17.

For each variable the number and percentage distributions of different options were calculated. As the study was mainly descriptive no further statistical analysis was needed.

\section{Results}

\section{Demographic characteristics of FSW}

The total number of the FSW studied was 431. Over half of them (52.7\%) were aged $<30$ years, with a mean age of 29.4 (SD 9.5) years and a median age of 27 years. Nearly a half of the FSW (49.2\%) had completed primary education and $19.1 \%$ had completed university education with a mean of 10.2 (SD 3.2) years of education; $59.2 \%$ could only read and write. Two-thirds (65.9\%) of the women had been married or were currently married. The age at first marriage was $15-25$ years for $80.3 \%$. The greatest proportion lived with their family (41.3\%) or a husband (36.7\%). As many as $70.8 \%$ had dependants and $57.6 \%$ were responsible for 3 or more dependants.

\section{Characteristics of sex work}

Women who depended solely on sex work for their living were $39.3 \%$ of respondents and $54.4 \%$ reported having other jobs. The most frequently reported jobs were hostess at a hotel or bar (14.8\%), housemaid (10.4\%) or dancer $(7.7 \%)$ (Table 1$)$. The majority of studied FSW were found to a have a monthly income from sex work of US\$ $<200(65.8 \%)$. The women's preferred methods of contacting clients were by waiting on the street (27.8\%), through an intermediate person $(21.8 \%)$ and from bars (20.0\%). Pimps and coffee shops were other places to find clients as reported by

\begin{tabular}{|c|c|c|}
\hline \multicolumn{3}{|c|}{$\begin{array}{l}\text { Table } 1 \text { Sociodemographic characteristics of the studied female sex workers } \\
(n=431)\end{array}$} \\
\hline Characteristic & No. & $\%$ \\
\hline \multicolumn{3}{|l|}{ Age (years) } \\
\hline$<20$ & 44 & 10.2 \\
\hline $20-$ & 183 & 42.5 \\
\hline $30-$ & 98 & 22.7 \\
\hline $40-$ & 51 & 11.8 \\
\hline $50-$ & 18 & 4.2 \\
\hline Unrecorded & 37 & 8.6 \\
\hline \multicolumn{3}{|l|}{ Education } \\
\hline Attended school & 262 & 60.8 \\
\hline \multicolumn{3}{|c|}{ Duration of education $(n=262)$} \\
\hline Primary (1-9 years) & 129 & 49.2 \\
\hline Secondary (10-12 years) & 83 & 31.7 \\
\hline University & 50 & 19.1 \\
\hline \multicolumn{3}{|l|}{ Marital status } \\
\hline Ever married & 283 & 65.7 \\
\hline \multicolumn{3}{|c|}{ Age at first marriage (years) $(n=283)$} \\
\hline$<15$ & 27 & 9.5 \\
\hline $15-$ & 148 & 52.5 \\
\hline $20-$ & 79 & 27.8 \\
\hline $25-$ & 23 & 8.1 \\
\hline $30+$ & 3 & 1.1 \\
\hline Unrecorded & 3 & 1.1 \\
\hline \multicolumn{3}{|l|}{ Living with: } \\
\hline Husband & 158 & 36.7 \\
\hline Male sexual partner & 20 & 4.6 \\
\hline Female sexual partner & 2 & 0.5 \\
\hline A friend & 25 & 5.8 \\
\hline Family & 178 & 41.3 \\
\hline Alone & 42 & 9.7 \\
\hline Unrecorded & 6 & 1.0 \\
\hline \multicolumn{3}{|c|}{ Having other job as a source of income } \\
\hline No & 172 & 39.9 \\
\hline Yes & 232 & 53.8 \\
\hline Unrecorded & 27 & 6.3 \\
\hline \multicolumn{3}{|l|}{ No. of dependants } \\
\hline 0 & 126 & 29.2 \\
\hline $1-2$ & 100 & 23.2 \\
\hline $3-4$ & 129 & 29.9 \\
\hline $5+$ & 76 & 17.6 \\
\hline
\end{tabular}

$11.6 \%$ and $10.7 \%$ respectively (Table 2).

Among the studied sex workers, $71.9 \%$ had been involved in sex work for a duration ranging from 1-10 years with a mean of 6.3 (SD 6.4) years, median 4 years (Table 2). Only $16.7 \%$ had previous experience of working outside greater Cairo. The mean age at which sex was first practised in exchange of money or some other benefits was 22.3 (SD 6.7) years. The 


\begin{tabular}{lcccccc}
\hline Table 2 Distribution of studied female sex workers & \multicolumn{3}{c}{ in relation to preferred methods of getting clients $(\boldsymbol{n}=\mathbf{4 3 1})$} \\
\hline Method of getting clients & \multicolumn{2}{c}{ First choice } & \multicolumn{2}{c}{ Second choice } & \multicolumn{2}{c}{ Third choice } \\
& No. & $\%$ & No. & $\%$ & No. & $\%$ \\
Waiting on street & 120 & 27.8 & 33 & 7.7 & 10 & 2.3 \\
Through intermediate person & 94 & 21.8 & 42 & 9.7 & 10 & 2.3 \\
From bars & 86 & 20.0 & 7 & 1.6 & 1 & 0.2 \\
Through pimps & 50 & 11.6 & 13 & 3.0 & 11 & 2.6 \\
From coffee shops & 46 & 10.7 & 50 & 11.6 & 17 & 3.9 \\
From hotels & 2 & 0.5 & 4 & 0.9 & 7 & 1.6 \\
From discotheques & 10 & 2.3 & 7 & 1.6 & 4 & 0.9 \\
From Internet & 1 & 0.2 & 1 & 0.2 & 1 & 0.2 \\
\hline
\end{tabular}

Respondents could give more than response.

age of first selling sex was $<15$ years for $4.7 \%$ of the women and $15-25$ years for $58.7 \%$. The majority had experienced arrest by the police $(70.1 \%)$ and $12.9 \%$ of those arrested reported sexual abuse during arrest at police stations.

More than one-third of participants had ever experienced unwanted pregnancy $(36.2 \%)$ and $34.8 \%$ had ever had an abortion (Table 3 ).

\section{Sexual practices}

The number of paying sexual partners in the previous month ranged between $2-5$ as reported by $70.8 \%$, while the number of non-paying partners was reported as only 1 by $51.5 \%$ and 0 by $42.5 \%$. The total number of sexual partners (paying and non-paying) in the previous month was $1-5$ for $63.8 \%$ of FSW. The number of sexual partners on the last day of work was 1 for $70.5 \%$ of the women (Table 3).

Vaginal sex was the most frequent type of sexual practice with paying partners (61.0\%), followed by kissing and cuddling (53.6\%) and oral sex (46.4\%). Superficial sex only was practised by $16.2 \%$ of paying sexual partners. The types of sexual practice by non-paying partners was vaginal sex $(65.1 \%)$, kissing and cuddling (52.9\%) and oral sex (48.2\%) (Table 4). Lesbian sex was practised by $3.0 \%$ of participants, some of them during menstruation

\section{Discussion}

More than half of FSW were aged < 30 years. Most of them had attended school and could read and write but some had completed university education. These findings are in accordance with findings of most studies on
FSW in the Middle East and North Africa $[12-15]$. On the other hand, most of the FSW had been married at a relatively young age. This contrasts with studies showing that in some cultures high dowry payments delay marriage for men and increase the median age of women at marriage. It has been

\begin{tabular}{|c|c|c|}
\hline \multicolumn{3}{|c|}{$\begin{array}{l}\text { Table } 3 \text { Distribution of studied female sex workers in relation to information } \\
\text { about their sexual history and clients }(n=431)\end{array}$} \\
\hline Variable & No. & $\%$ \\
\hline \multicolumn{3}{|l|}{ Age in years of first time selling sex } \\
\hline$<10$ & 2 & 0.5 \\
\hline $10-$ & 18 & 4.2 \\
\hline $15-$ & 127 & 29.5 \\
\hline $20-$ & 126 & 29.2 \\
\hline $25-$ & 51 & 11.8 \\
\hline $30+$ & 56 & 13.0 \\
\hline Unrecorded & 51 & 11.8 \\
\hline \multicolumn{3}{|l|}{ Duration of sex work in years } \\
\hline$<1$ & 16 & 3.7 \\
\hline $1-$ & 216 & 50.1 \\
\hline $5-$ & 94 & 21.8 \\
\hline $10-$ & 49 & 11.4 \\
\hline $15-$ & 24 & 5.6 \\
\hline $20+$ & 27 & 6.3 \\
\hline Unrecorded & 5 & 1.2 \\
\hline Previous sex work outside greater Cairo & 72 & 16.7 \\
\hline \multicolumn{3}{|l|}{ No. of paying sexual partners last month } \\
\hline 0 & 42 & 9.7 \\
\hline $1-$ & 149 & 34.6 \\
\hline 3- & 156 & 36.2 \\
\hline 5- & 70 & 16.2 \\
\hline $10+$ & 14 & 3.3 \\
\hline
\end{tabular}




\begin{tabular}{|c|c|c|}
\hline Variable & No. & $\%$ \\
\hline \multicolumn{3}{|l|}{ No. of non-paying sexual partners last month } \\
\hline 0 & 183 & 42.5 \\
\hline 1 & 222 & 51.5 \\
\hline 2 & 20 & 4.6 \\
\hline $3-5$ & 6 & 1.4 \\
\hline \multicolumn{3}{|l|}{ No. of total sexual partners last month } \\
\hline 0 & 21 & 4.9 \\
\hline $1-$ & 116 & 26.9 \\
\hline $3-$ & 172 & 39.9 \\
\hline $5-$ & 107 & 24.8 \\
\hline $10+$ & 15 & 3.5 \\
\hline \multicolumn{3}{|l|}{ No. of sexual partners last day practising sex } \\
\hline 1 & 304 & 70.5 \\
\hline 2 & 81 & 18.8 \\
\hline 3 & 28 & 6.5 \\
\hline 4 & 4 & 0.9 \\
\hline Unrecorded & 14 & 3.2 \\
\hline \multicolumn{3}{|l|}{ Monthly income from sex work (US\$) } \\
\hline$<100$ & 126 & 29.2 \\
\hline $100-$ & 158 & 36.7 \\
\hline $200-$ & 90 & 20.9 \\
\hline $500+$ & 45 & 10.5 \\
\hline Unrecorded & 12 & 2.8 \\
\hline Practise lesbian sex & 13 & 3.0 \\
\hline Practise lesbian sex during menstruation $(n=13)$ & 5 & 1.2 \\
\hline Ever had unwanted pregnancy & 156 & 36.2 \\
\hline Ever had an abortion & 150 & 34.8 \\
\hline Ever been arrested by police ${ }^{a}$ & 302 & 70.1 \\
\hline
\end{tabular}

${ }^{a} 5$ women did not answer.

argued that this trend encourages high rates of prostitution [16]. The same findings apply in other parts of the

world where rapid increases in education have accounted for increases in the median age at marriage, with a

\begin{tabular}{|c|c|c|c|c|}
\hline \multirow[t]{3}{*}{ Sexual practice } & \multicolumn{4}{|c|}{ Sexual practice preference } \\
\hline & \multicolumn{2}{|c|}{$\begin{array}{l}\text { Paying partners } \\
\qquad(n=431)\end{array}$} & \multicolumn{2}{|c|}{$\begin{array}{c}\text { Non-paying partners } \\
(\boldsymbol{n}=255)\end{array}$} \\
\hline & No. & $\%$ & No. & $\%$ \\
\hline Vaginal & 263 & 61.0 & 166 & 65.1 \\
\hline Anal & 38 & 8.8 & 21 & 8.2 \\
\hline Oral & 200 & 46.4 & 123 & 48.2 \\
\hline Superficial & 70 & 16.2 & 30 & 11.8 \\
\hline Kissing \& cuddling & 231 & 53.6 & 135 & 52.9 \\
\hline Group sex & 2 & 0.5 & 1 & 0.4 \\
\hline
\end{tabular}

Respondents could give more than response. subsequent increase in the demand for commercial sex $[17,18]$. This difference in age of marriage in this study compared to other studies elsewhere might be attributed to religious and cultural differences between communities.

FSW in Egypt behave as those in other countries in the region [14] in having other jobs rather than working openly as sex workers. Having a job facilitates them leaving the home and getting in contact with clients. These covering jobs included dancer, waitress, receptionist or housekeeper. Those who depended solely on sex work for their living represented only $36.6 \%$ of the sample and a majority were responsible for dependants. These findings might be due to the low income of most of FSW in contrast to their male clients, as when men's income rises, their ability to pay for commercial sex will rise [19].

The age at which sex was practised in exchange of money or some other benefits was concomitant with the age of marriage. It was observed in this study that majority of studied FSW were married below the legal age of marriage in Egypt which is 18 years. This early start renders them at greater risk for HIV infection [20]. Unwanted pregnancy was reported by $36.2 \%$ of participants, with subsequent experience of abortion for $34.8 \%$ of participants. Other studies in Nigeria and the Islamic Republic of Iran have reported similar findings $[21,22]$. This might be explained by the subservient position of FSW with little control over contraceptive methods, especially condom use, and the subsequent risks of unwanted pregnancy and abortion. This observed low use of condom and experience of unwanted pregnancy is a proxy for the exposure to unsafe sexual relations which may carry the risk for HIV infection. A study in the Nile delta among males aged 15-49 years showed a low use of condoms, with only $23.9 \%$ ever using condoms, mainly for contraception; only a quarter reported knowing how to use condoms properly [23]. 
This was a descriptive study exploring a very sensitive area of research in Egypt and its main purpose was to generate background findings for further research. This study had some limitations concerning the population sampling frame and sample selection that may limit the generalizability of the findings. However, it is extremely difficulty to accurately determine the study population in research concerning sex workers and there is no consensus on the definition of sex work. The study also lacked a qualitative assessment of
FSW and further qualitative research on this subject is needed in Egypt. Further research is also needed into the specific health-related aspects of FSW in Egypt and the risk factors for entering sex work, which may include lower education, low income, early marriage and experience of sexual abuse.

\section{Acknowledgements}

This study received funding from the Global Fund for Prevention of AIDS,
Tuberculosis and Malaria donated to the Ministry of Health and Population for conducting bio-behavioural studies among most at-risk populations in Egypt. The authors express their thanks and appreciation to Dr Mervat El-Gueneidy, Professor of Neuropsychiatric Nursing, University of Alexandria for her help. We thank all the women who participated in our study and those who helped by referring us to others, especially Al-Shehab, a nongovernmental organization working in the same field.

\section{References}

1. Rohaa SM, Hafez Y. Monitoring urbanization growth in Cairo city. Journal of Engineering and Applied Sciences, 2002, 49:667679.

2. Shahmanesh M, Wayal S. Targeting commercial sex-workers in Goa, India: time for a strategic rethink? Lancet, 2004, 364:1297-1299.

3. AIDS epidemic update. Geneva, Joint United Nations Programme on HIV/AIDS, 2009 (UNAIDS/09.36E/ JC1700E).

4. Report on the global AIDS epidemic. Geneva, Joint United Nations Programme on HIV/AIDS, 2004.

5. Chipfakacha V. Prevention of sexually transmitted diseases: the Shurugwi sex-workers project. South African Medical Journal, 1993, 83:40-41.

6. Wolffers I, van Beelen N, Brussa L: Violence, repression and other health threats. Sex workers at risk. Research for Sex Work, 2001, 4:1-32.

7. Ward $\mathrm{H}$ et al. Prostitution and risk of HIV: female prostitutes in London. British Medical Journal, 1993, 307:356-358.

8. Plummer FA et al. The importance of core groups in the epidemiology and control of HIV-1 infection. AIDS, 1991, 5(Suppl. 1):S169-S176.

9. Melbye M, Biggar RJ. Interactions between persons at risk for AIDS and the general population in Denmark. American Journal of Epidemiology, 1992, 135:593-602.

10. Spina $M$ et al. Human immunodeficiency virus seroprevalence and condom use among female sex workers in Italy. Sexually Transmitted Diseases, 1998, 25:451-454.

11. Amon J et al. Behavioral surveillance surveys. Guidelines for repeated behavioral surveys in populations at risk for HIV. Arlington, Virginia, Family Health International, 2000:210-230.

12. Abu-Raddad LJ et al. Epidemiology of HIV infection in the Middle East and North Africa. AIDS, 2010, 24(Suppl. 2):S5-S23.
13. Mahfoud Z et al. HIV/AIDS among female sex workers, injecting drug users and men who have sex with men in Lebanon: results of the first biobehavioral surveys. AIDS, 2010, 24(Suppl. 2):S45-S54.

14. Abdelrahim MS. HIV prevalence and risk behaviors of female sex workers in Khartoum, north Sudan. AIDS, 2010, 24(Suppl. 2):S55-S60.

15. Kriitmaa K et al. HIV prevalence and characteristics of sex work among female sex workers in Hargeisa, Somaliland, Somalia. AIDS, 2010, 24(Suppl. 2):S61-S67.

16. Caraël M, Glynn R. HIV, resurgent Infections and population change in Africa. Studies in Family Planning, 2010, 3:238-240.

17. Hirschman C. Premarital socioeconomic roles and the timing of family formation: a comparative study of five Asian societies. Demography, 1985, 22:35-59.

18. Brien MJ, Lillard LA. Education, marriage, and first conception in Malaysia. Journal of Human Resources, 1994, 29:1167-1204.

19. Rhodes T et al. Police violence and sexual risk among female and transvestite sex workers in Serbia: qualitative study. British Medical Journal, 2008, 337:a811.

20. Góngora-Biachi RA et al. Knowledge, behavior and seroprevalence towards HIV infection among female sex workers in Yucatan, Mexico. Revista Biomédica, 2002, 13:257-263.

21. Onyenechere E. Female condom in HIV/AIDS prevention among female commercial sex workers in Nigeria: a geographical perspective. Retrovirology, 2010, 7(Suppl. 1):118.

22. Ghahfarokhi et al. HIV/AIDS related knowledge and attitude among female sex workers in Tehran/Iran. Retrovirology, 2010, 7(Suppl. 1):130.

23. Kabbash IA et al. Condom use among males (15-49 years) in Lower Egypt: knowledge, attitudes and patterns of use: attitude and patterns of use. Eastern Mediterranean Heath Journal, 2007, 13:1405-1416. 